UDC: 811.111'276.6:371.3 https://doi.org/10.22190/JTESAP2104611Y

\title{
INTERLANGUAGE DEVELOPMENT OF TURKISH SPEAKERS OF ENGLISH: EXPLORING ORAL AND WRITTEN COMMUNICATION STRATEGIES ${ }^{a}$
}

\author{
Ilyas Yakut ${ }^{1}$, Erdogan Bada ${ }^{2}$ \\ ${ }^{1}$ Zonguldak Bulent Ecevit University, Turkey \\ ${ }^{2}$ Cukurova University \& Hakkari University, Turkey
}

\begin{abstract}
Language learners employ communication strategies (CSs) to avoid communication breakdowns in times of difficulty, and such strategies develop within strategic competence thanks to exposure to a target language. This research is designed as a developmental study aiming to investigate the possible effects of exposure to English as a foreign language on the use of CSs in the interlanguage of Turkish speakers of English. To attain this aim, we chose 20 Turkish learners of English from the beginner level, and they designated the topics they would speak and write about. Their oral and written performances on the topics were tested at the beginning prior to instruction, in the middle, and at the end of the academic year to observe whether CS usage altered over time. The findings revealed that participants resorted to different types of CSs in their speaking and writing tasks. The comparison of CS employment in each test showed that learners' CS preferences, as well as L1 and L2-based CSs, changed over time in both speaking and writing. Therefore, it is concluded that exposure to the target language may have a significant effect on the preference of CSs. The results of this study are significant as they suggested that CSs in interlanguage evolves from L1-based to L2-based strategies. The findings of this study have important implications for teaching English as a foreign language in reference to the effects of language exposure on the use of CSs in both oral and written performances of L2 learners.
\end{abstract}

Key words: Interlanguage, communication strategy, language exposure, speaking, writing

\section{INTRODUCTION}

Communicating in a first language (L1) is always more manageable, as it may not require frequent use of strategies to keep the communication going. However, communication in a second language (L2) is challenging and sometimes almost impossible due to linguistic inadequacies. Even though interlocutors want to keep the communication going smoothly in the L2 context, the limited knowledge of grammar, vocabulary or any other linguistic elements may force them to resort to certain strategies known as communication strategies (CSs) which generally emerge when a crisis occurs due to the speaker's inadequate control of

Submitted July $5^{\text {th }}, 2021$, accepted for publication July $22^{\text {nd }}, 2021$

Corresponding author: Zonguldak Bulent Ecevit University, Department of English Language and Literature, Turkey E-mail: ilyasyakut@beun.edu.tr

${ }^{a}$ This research is extracted from first author's MA thesis (Interlingual development of Turkish adult learners of English: L1 vs. L2-based communication strategy use) presented at Cukurova University Institute of Social Sciences 
the language. Færch and Kasper (1983) define communication strategies as being "[...] potentially conscious plans for solving what to an individual presents itself as a problem in reaching a particular communicative goal." (p. 36)

Using appropriate CSs is crucial as they help interlocutors keep the communication channel open. However, CSs may also cause communication breakdowns if they are not used appropriately. When a CS causes an idiosyncrasy, either overtly or covertly, sending the right message to the receiver can be rather difficult. Hence, choosing an appropriate $\mathrm{CS}$ for the situation requires competence in the language. Otherwise, the speaker would either stop communicating or employ L1-based strategies. Understanding the underlying reasons for different CS employment and the relationship between exposure to the $\mathrm{L} 2$ and the use of L1 and L2-based CSs will help teachers create a learning environment that may promote and encourage the use of L2 with utmost approximation to L1 speakers.

\subsection{Studies related to communication strategies}

Communicative competence (Hymes, 1972) and interlanguage (IL) (Selinker, 1972) can be regarded as milestones in second language acquisition (SLA) research, especially in CSrelated research. Selinker (1972) emphasized the importance of fossilization processes while acquiring or learning a second language. Hymes (1972), on the other hand, informed us about communicative competence, which is also known as the ability to convey the message and communicate appropriately within a specific context or topic (Brown, 1994). Following Hymes, Canale and Swain (1980) and Canale (1983) redefined communicative competence. The definition of communicative competence contains four main subcategories. They are grammatical competence, strategic competence, sociolinguistic competence (Canale \& Swain, 1980), and discourse competence (Canale, 1983).

Even though each subcategory explains one aspect of communicative competence, strategic competence is the key term that is directly related to CSs. According to Canale and Swain (1980), strategic competence refers to "[...] verbal and non-verbal CSs that may be called into action to compensate for breakdowns in communication due to performance variables or to insufficient competence" (p. 30). Strategic competence is needed when linguistic resources are insufficient to convey the message (Tarone, 1983). In addition, Yule and Tarone (1990) and Brown (1994) highlight that CSs may all be considered the subcategories of strategic competence.

Gaining popularity with the introduction of IL and communicative competence, various researchers have studied different perspectives of CSs. The study areas of CSs include definitions and taxonomies of CSs, teachability of CSs, the effects of task types on the use of CSs, and the effects of proficiency level on the use of CSs. A quick review of the related literature reveals various definitions of CSs due to adopting different conceptualizing perspectives (for more discussion, see Rababah, 2002). Despite differences in the definition of CSs among the scholars, the majority of definitions seem to gather around two criteria: problem-orientedness and consciousness (Dörnyei \& Scott, 1997; Rababah, 2002).

Similar to the definitions of CSs, a great variety of CS taxonomies are found in the related literature (for more discussion, see Yakut, 2013). Researchers develop their classification or taxonomy systems according to the approach they have adopted. For example, with the introduction of the interactional view, Tarone (1980) reformulated her taxonomy according to this view, while Færch and Kasper (1983) classified CSs 
according to views of psycholinguistic approach. In addition to these two approaches, taxonomies also differ due to linguistic or psychological approaches to defining and classifying CSs. As the researchers defend different perspectives while defining and classifying CSs, Rababah (2002) expresses that there is no clear consensus among the taxonomies of CSs, and utterances can be labeled under different subcategories across different taxonomies.

As different names for each CS may sometimes result in misunderstanding, Cook (1993) highlighted that there should be a standardized list of CSs; therefore, the subcategories would be similar to each other. However, Dörnyei and Scott (1997) claim that despite great differences among the taxonomies in terms of terminology, the core parts of the taxonomies are more or less the same. Similarly, Bialystok (1990) pointed out that taxonomies include similar concepts.

Some researchers have categorized CSs as L1 and L2-based strategies (Bada, 1993; Bialystok, 1983; Rababah, 2001). Even though they developed different taxonomy systems, these taxonomies reflect, by and large, similar concepts. L1-based CSs are generally known as CSs, which refer to transferring the data from the first language. However, L2-based CSs generally refer to overgeneralization. Since L1 and L2-based CSs constitute the basis of this study, it would be better to combine these classifications and see them in one list.

In addition to definitions and taxonomies of CSs, researchers have used different tasks to collect data for different purposes. As it has been proved by many researchers (DeKeyser, 1991; Dobao, 2001), task type affects the type and frequency of CSs employed by the speakers of L2. Therefore, the task type has been determined according to the aims of the study. According to Paramasiwam (2009), abstract tasks are more challenging and demanding in terms of communication abilities when compared to static and dynamic communication tasks. Therefore, the speakers talking on an abstract topic face more communication problems and breakdowns, resulting in more frequent CSs.

Although task type might have an impact on learner's language production, some scholars (Bialystok \& Kellerman, 1987; Bongaerts et al., 1987; Bongaerts \& Poulisse, 1989; Paribakht, 1985) support the idea of teaching the language, not the CSs, because it is assumed that if a learner knows more language, they can communicate more effectively in the L2. In addition, they speculate that interlocutors develop strategies in the L1, and they can be transferred to the $\mathrm{L} 2$ if the learners have the required competence in the L2.

For some, there is a relationship between language proficiency and the type and function of CSs employed while writing or speaking. Bialystok (1990) remarks that "What one must teach students of a language is not strategy, but language" (p. 147). Hence, it is believed that if the learner knows more language, they can benefit from L2-based CSs.

Dobao (2001) carried out a study aiming to explore the relationship between CS use and the proficiency level of Galician learners of English. Elementary, intermediate, and advanced level students were compared in terms of their CS preferences. The overall results showed that elementary level students resorted to CSs more frequently than others did. However, she also pointed out that when the students' productions are compared in terms of communicative goals, lexical and structural complexity, and richness, advanced level students resorted to CSs more systematically and consciously. They seemed to know more about the communicative effectiveness of the strategies, and thus they used CSs more appropriately.

Wannaruk (2003) conducted a study that aimed to determine whether language level affects the use of CSs. The results showed that students with a low level of proficiency 
resorted to L1-based and avoidance strategies, while students with middle and high levels of proficiency utilized more L2-based CSs when compared to L1-based CSs.

Similarly, Kalebic (2007) also found that types of CSs are not equally distributed in learner IL and concluded that proficiency level in L2 directly affects the type of CSs. Tajeddin and Alemi (2010) found in their study that increased proficiency triggers the use of L2-based CSs and reduces the use of L1-based and avoidance strategies.

Even though there seems to be a negative correlation between language proficiency and the frequency of CS employment, it should be borne in mind that the relationship between proficiency and CS employment cannot be explained by only analyzing the total numbers of CSs used in different levels. Hence, we should consider the complexity and richness of the topic and the context and the types and functions of the CSs while exploring CS employment. Otherwise, the pure frequencies may mislead the results of the findings.

The dynamics of communication via writing are different from speaking. First of all, speaking requires immediate reaction to other interlocutor's questions, comments, or proposals, yet writing does not always require an immediate reply. Secondly, the interlocutors can spend more time planning the message in writing, and thus the intended meaning can be transmitted more accurately. Finally, interlocutors have to guess readers' expectations and reactions to the text because the writer may not be able to change, clarify or reinterpret the message again. Therefore, written communication requires more cautiousness. Despite the wide range of CS research in speaking, not many studies have been carried out explaining the use of CSs in writing.

Sionis (1995) explored how two generations of French scientists employed CSs in their academic writing papers. The participants were divided into two groups. The results showed that message reduction strategies were higher than other strategies in both groups. Paralinguistic strategies and switching to mathematical language halfway through sentence or paragraph followed message reduction. In addition to these strategies, participants employed semantic avoidance, paraphrasing, and topic avoidance in their academic papers.

Chimbganda (2000) analyzed how first-year biology students utilize CSs to write answers in a biology exam. The results revealed that risk-taking, semantic simplification, and risk avoidance were the most common strategies. However, the comparison of lower and higher-level students suggested that semantic simplification and risk avoidance strategies were more common among learners with lower language proficiency.

Aliakbari and Allvar (2009) explored whether language proficiency affects the use of CSs while writing on a designated topic. They grouped the students into low and high proficiency English learners and compared the results of their writing performance regarding CS employment. The results showed that the low proficiency learners of English resorted to CSs more frequently than the high proficiency ones, which indicated a relationship between CS employment and level of proficiency.

The research results in CS usage show that if interlocutors move in the direction of L2 mastery, they will use more L2-based rather than L1-based CSs (Chen, 1990; Kalebic, 2007). Although there have been various studies related to the effects of language proficiency on the use of CSs (Dobao, 2001; Wannaruk, 2003), to the best of our knowledge, there is no longitudinal study investigating the relationship between exposure to L2 and the use of CSs. Therefore, this study suggests that the potential effects of language exposure on the use of CSs in terms of CS usage, both in writing and speaking, needs to be analyzed to find out how students overcome communication breakdowns before and after L2 exposure. 
Keeping this gap in mind, we aim to explore the potential contribution of a one-year instruction program of language education to the employment of communication strategy by English interlanguage speakers of Turkish university students. As the same group of students was observed three times during the academic year, the results might show how and why the students employ L1 and L2-based CSs. . In addition, the goal of this study is to observe what kinds of CSs learners use in written and spoken interactions with the research questions listed below:

- What kinds of communication strategies do Turkish EFL learners use in their oral communication tasks and writing tasks?

- What is the ratio of L1 and L2-based CSs used by Turkish EFL learners in their oral communication tasks and writing tasks?

- Does the amount of exposure to the target language affect the type and frequency of CSs employed by Turkish EFL learners? If so, how?

\section{METHODS}

This study is designed as a developmental study aiming to determine the effects of L2 instruction on CS usage in learners' speaking and writing. In this study, the researchers have also compared CSs in these productive skills.

\subsection{Participants}

The participants of this study were 20 A1-level university students at one of the intensive language programs in Turkey. In this program, students take a placement test that determines their level of English proficiency according to the Common European Framework of Reference (CEFR) at the beginning of the academic year. Then they embark on a one-year language program of study at their designated levels. The researchers decided to work with those who started at the lowest level possible (A1). The aim of choosing A1 level students was to see how the quality of their communication evolves throughout their one-year study and how they employ different types of CSs in a communication setting.

\subsection{Instrumentation}

For this study, participants specified three different topics to talk about and write about. The researcher encouraged them to choose the one that they felt most comfortable with. Since they took the speaking and writing tests three times a year, the students were not allowed to change the topics to observe how they could improve their language skills and use them while communicating in a one-year language instruction period. By remaining consistent with the topics after the first test, we aimed to prevent the potential effects of different topics on language production and CS usage in different tests.

The participants were interviewed on the designated topics for the speaking tests, and the researchers recorded them. While collecting the data for the speaking part, the students started talking about their topics, and one of the researchers asked some more questions to create an authentic communicative atmosphere. 
We collected the data for the writing part via free writing tasks covering the same topics as the speaking tasks. We gave an hour to students to write about their topics. They were not allowed to use a dictionary, and they could not ask questions to the instructor to explore how they could use their L2 repertoire while communicating in a written context.

\subsection{Data Analysis}

The oral and written products of the learners were transcribed and transferred to digital platforms for analysis. Qualitative data were analyzed through content analysis, and various CSs constituted the central theme of the study. The transcriptions were analyzed to find and tag each CS through a bottom-up approach.

Examining CSs and their types constituted the next step of the analysis. Strategies employed in speaking and writing were compared in terms of type and occurrence rates. Finally, statistical analyses of the tests were compared in terms of the frequency of L1\&L2-based strategies. Descriptive statistics related to strategies were utilized through SPSS 16.0 software package.

\subsection{Identification, Classification, and Analysis of CSs}

Ever since Selinker (1972) introduced the term CS, a wide variety of research has been conducted to investigate different aspects of CSs. Among the various studies, some of them (Bada, 1993; Bialystok, 1983 and 1990; Corder, 1983; Dörnyei \& Scott, 1995, 1997; Færch \& Kasper, 1983; Paribakht, 1985; Poulisse, 1993; Rababah, 2001; Tarone, 1977; Willems, 1987) mainly focused on identification and classification of the CSs. They developed different taxonomies of CSs and tagged them under different topics. However, when these taxonomies are closely examined, it can be recognized that they more or less reflect the same categories. In line with this view, after comparing the taxonomies of Bialystok (1983), Færch and Kasper (1983), Paribakht (1985) and Tarone (1977), Bialystok (1990) highlighted that taxonomies of CSs differ in terminology and general categorization, yet the main group of strategies across the taxonomies would be similar. However, this does not mean that all taxonomies are the same. From very early studies to the recent ones, it can be noticed that taxonomies have been evolving, and therefore, they have become more detailed.

In this study, we did not depend on specific taxonomies, but we used different taxonomies to analyze the data at hand. Dörnyei and Scott's $(1995,1997)$ "inventory of strategic devices" was used as a primary source because it compares and gives information about most taxonomies developed by other researchers. In addition to Dörnyei and Scott, we benefited from different taxonomies, especially while working on CS types. Taxonomies of Bada (1993), Bialystok (1983), and Rababah (2001) were used as main sources while classifying the strategies under L1 and L2-based strategies.

\section{RESULTS AND DISCUSSION}

The results obtained from speaking and writing tests concerning CS employment were given in tabular forms. Individual strategies with their types, numbers of occurrences, and percentages in each speaking test were presented in Table 1. 
Table 1 Communication strategies employed in speaking tests

\begin{tabular}{|l|l|r|r|r|r|r|r|}
\hline TYPE & STRATEGY & \multicolumn{2}{|c|}{ TEST 1 } & \multicolumn{2}{|c|}{ TEST 2 } & \multicolumn{2}{|c|}{ TEST 3 } \\
\cline { 2 - 7 } & & $\mathrm{N}$ & \multicolumn{1}{c|}{ \% } & $\mathrm{N}$ & $\%$ & $\mathrm{~N}$ & $\%$ \\
\hline \multirow{2}{*}{ L1-BASED } & Code-switching & 254 & 60,62 & 105 & 29,66 & 51 & 19,62 \\
& Literal translation & 8 & 1,91 & 20 & 5,65 & 13 & 5,00 \\
\hline \multirow{5}{*}{ L2-BASED } & Approximation & 7 & 1,67 & 8 & 2,26 & 4 & 1,54 \\
& Asking for clarification & 25 & 5,97 & 22 & 6,21 & 7 & 2,69 \\
& Asking for repetition & 0 & 0,00 & 7 & 1,98 & 0 & 0,00 \\
& Expressing non-understanding & 2 & 0,48 & 12 & 3,39 & 0 & 0,00 \\
& Feigning understanding & 0 & 0,00 & 15 & 4,24 & 11 & 4,23 \\
& Message abandonment & 4 & 0,95 & 0 & 0,00 & 1 & 0,38 \\
& Other repetition & 20 & 4,77 & 11 & 3,11 & 27 & 10,39 \\
& Paraphrase & 0 & 0,00 & 2 & 0,56 & 2 & 0,77 \\
& Self-repetition & 92 & 21,96 & 142 & 40,11 & 139 & 53,46 \\
& Topic avoidance & 2 & 0,48 & 2 & 0,56 & 0 & 0,00 \\
& Use of all-purpose words & 0 & 0,00 & 2 & 0,56 & 0 & 0,00 \\
& Use of filler & 1 & 0,24 & 0 & 0,00 & 4 & 1,54 \\
& Use of similar sounding words & 0 & 0,00 & 3 & 0,85 & 0 & 0,00 \\
& Word coinage & 4 & 0,95 & 3 & 0,85 & 1 & 0,38 \\
\hline TOTAL & & 419 & 100,00 & 354 & 100,00 & 260 & 100,00 \\
\hline
\end{tabular}

According to Table 1, the participants used 1033 CSs in total. Out of 1033 CSs, 419 $(40,56 \%)$ strategies were employed during the first speaking test. However, there was a decrease in CS employment in the second test as $354(34,27 \%)$ CSs emerged. In addition, CSs were used 260 times in the last test, constituting $25,17 \%$ of the total strategy employment. The chi-square test result also showed a statistically significant difference in the use of CSs across the tests $(\mathrm{p}=, 000)$. Therefore, it can be suggested that there might be a relationship between the exposure to the L2 and CS employment rate. Similarly, according to the findings of Hyde (1982) and Poulisse and Schils (1989), learners at lower levels resort to more CSs when compared to learners at higher levels. By referring to these findings, it can be deduced that if the language repertoire allows learners to express their intended message adequately, they resort to fewer CSs.

As shown in Table 1, 62,53\% of CSs were L1-based, while only 37,47\% were L2-based in the first test. According to the results, L2-based CSs $(64,69 \%)$ were more frequently used compared to L1-based CSs $(35,31 \%)$ in the second test. Furthermore, it was observed that the percentage of L1-based CSs in the last test was reduced to 24,62\%, while L2-based CSs rose to $75,38 \%$. Overall speaking, L2-based CSs were more common compared to L1-based CSs except Test 1. However, it was also observed that the numbers of both L1 and L2-based CSs were limited in the last test compared to the first two tests, and thus it can be deduced that participants in the last test needed fewer CSs to continue communicating. In addition to a significant difference in L1 and L2-based CS usage in each test, the Pearson chi-square test result reveals a statistically significant difference across tests $(p=, 000)$.

The overall findings suggest that types of CSs changed over time. Such a change can be attributable to the fact that the amount of exposure to the L2 significantly affected CS types. As the learners did not have sufficient L2 background to solve problems they encountered when they took the first test, they had to use their L1 repertoire. However, when they were 
exposed to L2 in their intensive language program, they apparently started to benefit more from their L2 repertoire to reach their communicative goals. Our results show similarities to Kalebic's (2007) findings, who conducted a study with Croatian participants regarding the effects of proficiency on the use of CSs. According to Kalebic's findings, learners at lower levels resorted to L1-based CSs more frequently while more proficient learners preferred L2based CSs. Even though our study does not directly deal with proficiency, it is evident that proficiency can increase with the help of exposure to the L2.

In addition to overall CS usage and their types, we also found that individual CS usage changed or fluctuated across the tests, which can be attributable to the fact that exposure to the L2 can be accepted as one of the main reasons for the different CS employments in the tests. Even though most of the CSs differed in terms of frequency and percentage in each test, the rates of code-switching, literal translation, asking for clarification, and self-repetition might give more insight into the relationship between L2 exposure and CS preference.

Out of 11 different CSs employed in the first speaking test, code-switching was resorted to $254(60,62 \%)$ times by the learners, and it was the most frequent CS. However, among 14 different CSs, code-switching was used $105(29,66 \%)$ times during the second test. In the last test, however, participants resorted to 12 different kinds of CSs, and code-switching constituted only $19,62 \%$ of the total CS usage. Regarding the use of code-switching in each test, participants reduced code-switching usage over time due to exposure to English which was supported by the Chi-square test result $(p=, 000)$. Despite observing a statistically significant decrease over time in code-switching usage, we need to note that it was among the most common CS in all tests. Different functions of code-switching were illustrated in the extracts below.

[1] The his department international < foreign $>$ ilişkiler $<$ /foreign $>$

[2] Because I like my university. My university is very good $<$ foreign $>$ işte $</$ foreign $>$ very nice university.

[3] S: Also, I have one brother and two sisters. My small brother is is a is a student in <foreign>in demeyelim tamam</foreign> primary school in the primary school.

[4] I: Okay. Very good. How about your father? What does he do? $\mathrm{S}$ : My father is $<$ foreign $>$ ne yapar dediniz değil mi hocam $</$ foreign $>$ I: Yes. What is his job?

The speaker in [1] tried to communicate in the L2 as much as possible. Nevertheless, she resorted to the Turkish equivalent of 'relations'. Similar to the findings of Yakut (2019), it has been recognized that learners employed code-switching consciously when they understood that they were not able to continue communicating in the L2. Contrary to codeswitching employment because of linguistic inadequacies, it was also observed that learners sometimes used code-switching as a gap-filler automatically and sometimes unconsciously. The speaker in [2] was explaining why he likes his university, yet he used 'işte' which means 'that is' in order to keep the communication going. However, such usages did not affect the communication as they were not used to convey a message. The speaker in [3] was not sure whether she should use a preposition with 'primary school', and she talked to herself, saying, 'let's not use in', but her aim was not to communicate with the interlocutor by switching to L1. She only told what she was thinking. She might have uttered what she thought loudly either to illustrate that she reflected her cognitive processes or to keep the 
communication channel open by saying something. The last code-switching observed in our data is that the speaker resorts to code-switching to ask for confirmation (Dörnyei \& Scott, 1995; 1997). According to Dörnyei and Scott (1995, 1997), Lafford (2004), and Nakatani (2005), confirmation check or asking for confirmation is a request, question, or repetition which is used to check whether the speaker himself has correctly understood the question or the utterance. Their examples of asking for confirmation are only given in L2. However, our data shows that asking for confirmation can also take place in L1. The speaker in [4] resorted to code-switching to clarify whether he understood the question correctly by saying, 'Sir, you asked his job, right?' and the instructor confirmed the message by paraphrasing the question he asked before.

Similarly, asking for clarification declined from the first to the last. As presented in Table 1, asking for clarification emerged $25(5,97 \%)$ times in the first test while it was observed $22(6,21 \%)$ times in the second test. Contrary to the first two tests, asking for clarification was only used $7(2,69 \%)$ times in the last test. Although this strategy is not directly related to the participants' production, such a decrease indicates that the participants' ability to understand the message properly increased over time; thus, they did not request clarification from the instructor. In [5], the participant could not recall legend's meaning and resorted to asking for clarification to respond to the question.

[5] I: Okay. When I ask you this question, "who is the legend of Galatasaray?" what would you say?

S: Legend? What does it mean, legend?

In contrast to the CSs that decreased over time, it was observed that employment of literal translation and self-repetition increased. As can be seen in Table 1, literal translation was used eight times, constituting $1,91 \%$ of the total CS use in the first test. However, it was employed $20(5,65 \%)$ times and $13(5,00 \%)$ times in tests two and three, successively. Even though a decrease was observed between the last two tests, it is still evident that participants resorted to literal translation in the second and the last test more frequently than they did in the first test. While literal translation caused idiosyncrasies similar to code-switching, participants tried to express themselves in English despite being un/aware of using inappropriate words or structures.

[6] My father is honey sell.

[7] She put hard rules.

[8] I hope building engineer.

The utterance in [6] illustrates how learners transfer their L1 sentence structures to their L2 speech. Although the words are all in English in that example, the arrangements of the subject, object, and the verb represent the Turkish grammar system. Contrary to [6], the participants in [7] and [8] did not transfer the grammar of Turkish to English, yet they directly translated the Turkish words into English and made sentences that are not meaningful in the L2. In [7], the participant tried to say that her mother establishes harsh rules, yet she used words directly translated from her L1. On the other hand, the participant used 'building engineer' instead of 'civil engineer' in [8].

Another strategy whose employment increased over time was self-repetition. According to Table 1, self-repetition constituted 21,96\% (92) of the total strategy usage 
in the first test. However, its percentage increased to $40,11 \%$ (142) in the second test and $53,46 \%$ (139) in the last test. Self-repetition was the second most frequently used CS in the first test, while it was the most common CS in the last two tests. In addition to descriptive analysis, the chi-square test result also showed a statistically significant difference in the use of self-repetition across the tests $(p=, 002)$. The extracts taken from learners' speech illustrate forms and functions of self-repetitions.

[9] And he he has transportation company.

[10] And my big brother, my big brother name is Yusuf.

[11] When you start the play, firstly you $\langle$ trunc $>\underline{\text { mu }}</$ trunc $>$ you must create you must create a avatar.

[12] There are a lot of story, a lot of different stories.

As shown in the examples, the participants repeated the words or phrases to either gain time or modify their utterances. According to the extracts, we can say that repetitions could occur at word and phrase-level confirming Bada's (2010) suggestions regarding the forms of repetitions. The first two examples indicate how learners purely repeated the exact words and phrases to gain time. However, the last two examples show that learners employed self-repetitions as self-repairs to correct their productions or add new information. In [11], the learner was not able to pronounce the word 'must' correctly on the first try, and thus, he truncated the word at first. However, he tried again and corrected his pronunciation on the second try. In [12], the speaker not only corrected his mistake but also added new information to his speech. As there is a modification (Bada, 2010), such repetitions are accepted as self-repair.

In sum, the distributions of both L1 and L2-based CSs and individual strategy employment in their speaking suggest that types and frequencies of CSs change over time as a result of the instruction received throughout the academic year.

Similar to the analysis we made in speaking tests, CS employment in learners' writings were also explored. The nature of writing is different from speaking; therefore, CSs employed during each writing test were given in isolation. Table 2 presented below shows the types of CSs and individual strategy usage in each test.

According to Table 2, L1-based strategies were preferred more frequently than L2based CSs in all tests. The first test results showed that out of 69 strategy employment, L1-based CSs emerged $55(79,71 \%)$ times while L2-based CSs occurred 14 (20,29\%) times. However, in the second test, L1-based CSs occurred 35 (74,47\%) times, and L2based CSs emerged only $12(25,53 \%)$ times. In the last test, participants lessened their L1based CSs to 28 , albeit accounting for $70,00 \%$ of the total strategy usage, while they employed L2-based CSs $12(30,00 \%)$ times. Despite common usage of L1-based CSs in each test, learners decreased their L1-based CS usage by ten percent from the first to the last.

As shown in Table 2, participants resorted to eleven strategies during their writing tests. They employed nine different CS types in the first test, eight in the second, and seven in the last. Out of eleven kinds of CSs, three were categorized under L1-based strategies while the rest were L2-based CSs. 69 CSs were used in the first test while they were reduced to 47 in the second and 40 in the third. A cross-test chi-square analysis revealed a statistically significant difference in the dispersion of CS employment across the tests $(p=, 012)$. 
Table 2. Communication strategies employed in writing tests

\begin{tabular}{|l|l|r|r|r|r|r|r|}
\hline TYPE & STRATEGY & \multicolumn{2}{|c|}{ TEST 1 } & \multicolumn{2}{|c|}{ TEST 2 } & \multicolumn{2}{|c|}{ TEST 3 } \\
\cline { 2 - 7 } & & $\mathrm{N}$ & \multicolumn{1}{c|}{$\%$} & $\mathrm{~N}$ & \multicolumn{1}{c|}{ \% } & \multicolumn{1}{c|}{$\%$} \\
\hline \multirow{3}{*}{ L1-BASED } & Code-switching & 11 & 15,94 & 5 & 10,64 & 5 & 12,50 \\
& Foreignizing & 3 & 4,35 & 2 & 4,26 & 3 & 7,50 \\
& Literal translation & 41 & 59,42 & 28 & 59,57 & 20 & 50,00 \\
\hline \multirow{5}{*}{ L2-BASED } & Approximation & 4 & 5,80 & 5 & 10,64 & 4 & 10,00 \\
& Message abandonment & 1 & 1,45 & 0 & 0,00 & 0 & 0,00 \\
& Overgeneralization & 3 & 4,35 & 0 & 0,00 & 5 & 12,50 \\
& Paraphrase & 0 & 0,00 & 0 & 0,00 & 1 & 2,50 \\
& Repetition & 1 & 1,45 & 1 & 2,13 & 0 & 0,00 \\
& Use of all-purpose words & 0 & 0,00 & 2 & 4,26 & 2 & 5,00 \\
& Use of Filler & 1 & 1,45 & 1 & 2,13 & 0 & 0,00 \\
& Word Coinage & 4 & 5,80 & 3 & 6,38 & 0 & 0,00 \\
\hline & TOTAL & 69 & 100,00 & 47 & 100,00 & 40 & 100,00 \\
\hline
\end{tabular}

Among the eleven different CSs identified in participants' writings, the literal translation is reported as the most frequently used CS in all tests. However, it is also observed that the use of literal translation decreased over time. While it emerged $41(59,42 \%)$ times in the first test, this strategy occurred $28(59,57 \%)$ times in the second and $20(50,00 \%)$ times in the last. Code-switching has also played an essential role while struggling with communication problems in the writing tests. It was used 11 times, accounting for $15,94 \%$ of the total strategy employment in the first test. However, code-switching was employed only five times in the second $(10,64 \%)$ and the third tests $(12,50 \%)$.

[13] Messi is year 64 pounte earn.

[14] His girlfriend is Adriana Lima. But they are <foreign>hiç uyuşmuyorlar $</$ foreign $>$.

In [13], the participant tried to say that 'Messi earns 64 pounds in a year', yet he only translated the words from Turkish to English without obeying the sentence structure of English. Therefore, the outcome consists of a list of English words causing idiosyncrasy and breakdowns in the participant's communication which might be because the participant did not know how to produce the sentence by applying the rules of the L2. Hence, he resorted to literal translation to keep the communication going.

In [14], the participant tried to say that 'they cannot get on well', yet his language repertoire did not allow him to utter it in L2; hence he switched to his L1 to complete the message. A mixture of Turkish and English in [14] clearly indicates that even though the participants were not forced to communicate in the L2 during the tests, they seemed to be aware that using their L1 while communicating in the L2 would not be appropriate. Therefore, they did not switch to their L1 as long as they could transmit the message in L2.

A decrease was also observed in word-coinage. Table 2 reveals that participants resorted to word-coinage four times in the first test and three times in the second, whereas they did not employ word-coinage in the last test. Word-coinage can be actualized by creating new words by adding prefixes or suffixes to an already existing English word, yet the native English speakers do not use the newly created words. Therefore, they caused idiosyncrasies in the 
participants' writing, and the receiver could not adequately understand the message. The results of word-coinage imply that participants realized that using a non-existing word in the L2 did not help them reach their communicative goal; thus, they gave up employing wordcoinage. Instead of using word-coinage, participants resorted to overgeneralization five times $(12,50 \%)$ in the last test to avoid communication breakdowns.

[15] He clothes sport.

As can be seen in [15], the learner tried to say 'he wears casual clothes' yet did not know or remember 'wear' that should have been used in order to convey the intended meaning. Therefore, he added -es at the end of 'cloth', which is a noun, and he created a new verb to compensate for his linguistic deficiency. As word coinage results in idiosyncrasy in his utterance, the sentence does not convey a clear, meaningful message.

Contrary to the CSs that decreased over time, we realized that the use of paraphrasing and all-purpose words increased. Even though they were employed infrequently, such strategies imply that instead of giving up or benefiting from the L1-based CSs, participants tried to communicate in the L2 despite not finding the exact word they needed to convey the original message. Finally, even though repetition and use of fillers contradict the nature of communicating through writing, such usages were identified only in the first two tests. However, the participants did not prefer these two CSs in the last test. This shows that participants were not aware of the fact that repetition and fillers cannot be used while communicating through writing. Nevertheless, as the results of the last test show, they noticed that the purpose of repetition and filler did not meet their needs in writing. Therefore they did not resort to them.

As the findings of writing tests reveal, participants resorted to different CSs to compensate for their linguistic inadequacies. Even though the literal translation was reported as the most frequently used CS among others, it was observed that most of the strategies, especially literal translation, were reduced to limited numbers over time. As the participants' L2 repertoire improved, they did not resort to L1-based CSs as frequently as they did previously. Furthermore, they also started choosing CSs more appropriately to overcome breakdowns. The overall results of the writing tests indicated that the use of CSs changed over time because of a better L2 repertoire which probably developed due to language exposure. Still, despite developing their L2 abilities over time, the learners used L1-based CSs more frequently than L2-based CSs in their writings. However, their reliance on their L1 decreased with the help of language instruction.

\section{DISCUSSION}

By referring to the findings of the study which aimed to observe errors and compensatory strategies used in texts prepared by Norwegian learners of English, Olsen (1999) highlights "[T]he L1 of the learners plays an important role and is used for reference and assistance in most cases" (p. 201). As seen in this study, participants resorted to different types of CSs for different purposes in speaking and writing tests. The use of CSs in speaking is different from the ones we observed in writing which can be attributed to their distinctively different natures. However, another difference observed in our study was that CS preference also varies across the tests within each communication type. Therefore, the present study indicates that exposure to the L2 plays an essential role in selecting CSs. 
The current study did not directly observe the relationship between proficiency and CS employment in the learners' speaking. Despite this, regarding the use of code-switching strategy, we observed some similarities between our study and other studies investigating the effects of proficiency level on the use of CSs. As Kalebic (2007) highlights, students at lower levels employ code-switching more frequently when compared to intermediate learners. Similarly, upper-intermediate learners do not resort to code-switching as frequently as intermediate learners do. In addition, Ting and Phan's (2008) results indicate that codeswitching is not employed frequently by advanced-level learners while low-proficiency learners generally prefer it. In line with these studies, we also observed a similar tendency among our participants. Even though the distribution of code-switching in Kalebic (2007) and Ting and Phan (2008) showed similarities to the results of our tests, these scholars highlight that code-switching was used only to compensate for linguistic deficiencies. However, in addition to linguistic insecurity, code-switching was also employed as a gap-filler using empty words in their L1. According to Yakut's (2019) findings, the learners can use such switches consciously or unconsciously. Furthermore, we observed that participants sometimes resorted to code-switching to show that they were thinking about the utterance they were planning to produce. In addition, the participants in our study used code-switching to ask for confirmation.

From the total numbers of CSs perspective, we observed that numbers of total strategy employment in each test decreased over time due to improving L2 repertoire. Similarly, Poulisse and Schils's (1989) study with Dutch English learners indicated that advanced English learners resorted to fewer CSs than the less proficient ones did in their speaking performance. Therefore, even though the L1 backgrounds of learners in both Poulisse and Schils's and this study were different, we observed a positive correlation between the numbers of CSs being employed by Dutch and Turkish learners of English. Similar to Wannaruk's (2003) findings regarding L1 and L2-based CS employment, we found that the participants resorted to L1-based CSs more frequently than L2-based ones before the language instruction. However, due to gaining competence in the L2, participants preferred L2-based CSs more frequently and decreased L1-based CSs.

We observed that literal translation and code-switching were employed quite frequently compared to other strategies regarding the participants' writing performance. Yarmohammedi and Seif (1992) highlighted that the percentage of literal translation was significantly higher than the other strategies in the learners' writing. Similarly, we found that the percentage of literal translation was higher than the other CSs. As observed in both studies, learners resorted to literal translation quite frequently due to the nature of the writing task, which usually allows learners to spend more time thinking about the message they will produce.

Even though code-switching was observed to be the second most frequently used strategy in the learners' writing, its use was limited to 21 (13,58\%) in this study. As Olsen (1999) emphasized, participants did not resort to code-switching as frequently as they did in speaking because of the nature of the task. This might be because participants perceived code-switching as the least effective or appropriate strategy that they could use in their writing.

Concerning total strategy employment in the writing of the participants in each test, similar to Aliakbari and Allvar (2009), we found a negative correlation between the frequency of CS employment and proficiency level. It was observed that participants decreased CS usage over time due to gaining more competence in the L2. Aliakbari and Allvar (2009) highlighted that more proficient learners resort to fewer CSs than less proficient (beginners) ones do in their writing. Despite finding similar results to our study in their study, they did not observe the same group of participants over a period of time. Thus participants' developmental 
stages of IL were not taken into consideration. Furthermore, they only compared low and high proficiency learners' writing performances while we observed our participants for one year to observe better the effects of language exposure on the use of CS employment. Nevertheless, there are still similarities between the two studies, probably due to the relationship between language exposure and level of proficiency.

Observing that the dynamics of both speaking and writing are different, this study can suggest that strategy employment was relatively specific to each of these skills. However, regarding overall frequency, we can state that exposure to the L2 has a great deal to contribute to the shift from L1 to L2-based strategies.

\section{CONCLUSIONS}

Our study highlights that despite not getting education of a specific CS usage, learners try to use either their L1 or L2 to compensate for linguistic deficiencies in speaking and writing. As the students improve their L2 capacity over time, they start using their L2 repertoire much more frequently when compared to their L1. Even though strategies may help them communicate with the interlocutors, most CSs (notably L1-based CSs) cause idiosyncrasies in speaking and writing; in other words, they decrease the efficiency and quality of communication. However, when the students start using their L2 effectively, they can transmit the message with more ease. It can be implied from this present study that learners of a specific language can cope with crises they encounter while communicating by resorting to strategies or solutions that they develop or transfer from their L1. In light of our study, it can be recommended that rather than direct exposure to strategy training, creating a learner-friendly environment aiming to expose the learners to the L2 as much as possible may help them improve their L2 skills and develop different and practical problem-solving strategies in L2 speaking and writing. So, the main focus of language teaching should be teaching the language itself rather than focusing on how to overcome specific problems by resorting to temporary solutions.

\section{REFERENCES}

Aliakbari, M., \& Allvar, N., K. (2009). Communication strategies in the written medium: The effect of language proficiency. Linguistik Online, 40, 4-13.

Bada, E. (1993). Phonemic identifications in English: A case of interlingual transfer by adult speakers of Turkish, Japanese, and Arabic [Unpublished Ph.D. dissertation]. The University of Exeter, Exeter.

Bada, E. (2010). Repetitions as vocalized fillers and self-repairs in English and French interlanguages. Journal of Pragmatics, 42, 1680-1688.

Bialystok, E. (1983). Some factors in the selection and implementation of communication strategies. In Claus Færch \& Gabriele Kasper (Eds.), Strategies in interlanguage communication (pp. 100-118). London: Longman.

Bialystok, E. (1990). Communication strategies. Oxford: Blackwell.

Bialystok, E., \& Kellerman, E. (1987). Language strategies in the classroom. In B.K. Das (Ed.), Communication and learning in the classroom community (pp. 160- 175). Singapore: SEAMEO Regional Language Centre. 
Bongaerts, T., \& Poulisse, N. (1989). Communication strategies in L1 and L2: Same or different? Applied Linguistics, 10, 253-268.

Bongaerts, T., Kellerman, E., \& Bentlage, A. (1987). Perspectives and proficiency in L2 referential communication. Studies in Second Language Acquisition, 9, 171-200.

Brown, H., D. (1994). Principles of language learning and teaching. New Jersey: Prentice-Hall.

Canale, M. \& Swain, M. (1980). Theoretical bases of communicative approaches to second language teaching and testing. Applied Linguistics, 1, 1-47.

Canale, M. (1983). From communicative competence to communicative language pedagogy. In J. C. Richards \& R. W. Schmidt (Eds.), Language and Communication (pp. 2-15). New York: Longman.

Chen, S. (1990). A study of communication strategies in interlanguage production by Chinese EFL learners. Language learning, 40(2), 155-187.

Chimbganda, A. B. (2000). Communication strategies used in the writing of answers in biology by ESL first-year science students at the University of Botswana. English for Specific Purposes, 19(4), 305-329.

Cook, V. (1993). Linguistics and second language acquisition. New York: St. Martin's Press.

Corder, S. P. (1983). Strategies of communication. In C. Færch \& G. Kasper (Eds.), Strategies in interlanguage communication (pp. 15-18). London: Longman.

DeKeyser, R. (1991). Foreign language development during a semester abroad. In B. Freed (Ed.), Foreign language acquisition research and the classroom (pp. 104- 119). Lexington, Mass.: DC Heath and Co.

Dobao, A. M. F. (2001). Communication strategies in the interlanguage of Galician students of English: The influence of learner and task-related factors. Atlantis, 23(1), 41-62.

Dörnyei, Z., \& Scott, M. L. (1995). Communication strategies: An empirical analysis with retrospection. In J.S. Turley \& K. Lusby (Eds.), Selected papers from the proceedings of the 21st annual symposium of the Deseret Language and linguistics society (pp. 155-168). Provo, UT: Brigham Young University.

Dörnyei, Z., \& Scott, M. L. (1997). Communication strategies in a second language: Definitions and taxonomies. Language Learning, 47, 173-210.

Færch, C., \& Kasper, G. (1983). Plans and strategies in foreign language communication. In C. Færch \& G. Kasper (Eds.), Strategies in interlanguage communication (pp. 2060). London: Longman.

Hyde, J. (1982). The identification of communication strategies in the interlanguage of Spanish speakers of English. Anglo-American Studies, 2(1), 13-30.

Hymes, D. (1972). On communicative competence. In J. Pride, \& J. Holmes (Eds.), Sociolinguistics: Selected readings (pp.269-93). Harmondsworth: Penguin.

Kalebic, S., C. (2007). On the use of compensatory strategies in learner interlanguage. In J. Horvath, \& M. Nikolov (Eds.), Empirical studies in English applied linguistics (pp. 269-279). Pecs: Lingua Franca Csoport.

Lafford, B. A. (2004). The effect of the context of learning on the use of communication strategies by learners of Spanish as a second language. Studies in Second Language Acquisition, 26(2), 201-225.

Nakatani, Y. (2005). The effects of awareness-raising on oral communication strategy use. Modern Language Journal, 89, 75-90.

Olsen, S. (1999). Errors and compensatory strategies: A study of grammar and vocabulary in texts written by Norwegian learners of English. System, 27, 191-205. 
Paramasiwam, S. (2009). Language transfer as a communication strategy and a language learning strategy in a Malaysian ESL classroom. Asian EFL Journal, 11(1), 192-229.

Paribakht, T. (1985). Strategic competence and language proficiency. Applied Linguistics, 6, 132-146.

Poulisse, N. (1993). A theoretical account of lexical communication strategies. In R. Schreuder, \& B. Weltens (Eds.), The bilingual lexicon (pp. 157-189). Amsterdam: John Benjamins.

Poulisse, N., \& Schils, E. (1989). The influence of task- and proficiency-related factors on the use of communication strategies: A quantitative analysis. Language Learning, 39, 15-48.

Rababah, G. (2001). An investigation into the strategic competence of Arab learners of English at Jordanian universities [Unpublished Ph.D. dissertation]. The University of Newcastle, Upon Tyne.

Rababah, G. (2002). Second language communication strategies: Definitions, taxonomies, data elicitation methodology, and teachability issues, a review article, ED472698.

Selinker, L. (1972). Interlanguage. International Review of Applied Linguistics (IRAL), 10(3), 209-231.

Sionis, C. (1995). Communication strategies in the writing of scientific research articles by non-native users of English. English for Specific Purposes, 14(2), 99-113.

Tajeddin, Z., \& Alemi, M. (2010). Less proficient vs. more proficient L2 learners' preferences for compensation strategies: L1-based, L2-based, and non-linguistic. Linguistic and Literary Broad Research and Innovation, 1(2), 48-55.

Tarone, E. (1977). Conscious communication strategies in interlanguage: A progress report. In H. D. Brown, C.A. Yorio, \& R.C. Crymes (Eds.), TESOL (pp. 194-203). Washington: TESOL.

Tarone, E. (1980). Communication strategies, foreigner talk, and repair in interlanguage. Language Learning, 30(2), 417-431.

Tarone, E. (1983). Some thoughts on the notion of "communication strategy". In C. Færch, \& G. Kasper (Eds.), Strategies in interlanguage communication (pp. 61- 74). London: Longman.

Ting, S., \& Phan, G. (2008). Adjustment in communication strategy use to interlocutor's language proficiency. Prospect: Australian TESOL Journal, 23(1), 28-36.

Wannaruk, A. (2003). Communication strategies employed by EST students. SLLT 12, 1-18.

Willems, G. (1987). Communication strategies and their significance in foreign language teaching. System 15(3), 351-364.

Yakut, I. (2013). Interlingual development of Turkish adult learners of English: L1 vs. L2 communication strategy use [Unpublished master's thesis]. Çukurova University.

Yakut, I. (2019). Drawing on strategic competence in EFL context: The effects of addressee's L1 background on compensation strategy use. In H. Yilmaz, E. Yucel, \& M. S. Ozturk (Eds.), A general perspective on foreign language teaching III (pp. 147165). Konya: Çizgi Publishing House.

Yarmohammadi, L., \& S. Saif. (1992). More on communication strategies: Classification, resources, frequency, and underlying processes. IRAL 30(3), 223- 232.

Yule, G. \& Tarone, E. (1990). Eliciting the performance of strategic competence. In Scarcella, R., E. Andersen \& S. Krashen (Eds.), Communicative competence in a second language (pp. 179-194). New York: Newbury House. 